\title{
Continuous Multiphase Flow Nitration and Cryogenic Flow Formylation: Enabling Process Development and Manufacturing of Pharmaceutical \\ Intermediates
}

\author{
Supporting Information
}

Benoit Cardinal-David, ${ }^{* 1}$ Kaid C. Harper, ${ }^{1}$ Anuj Verma, ${ }^{1}$ David Hanna, ${ }^{1}$ Daniel D. Caspi, ${ }^{1}$

Christopher Vitale, ${ }^{1}$ Jeffrey T. Bien, ${ }^{1}$ Zhe Wang, ${ }^{1}$ and Moiz Diwan ${ }^{1}$

${ }^{1}$ Process Research and Development, AbbVie, Inc., 1401 Sheridan Road, North Chicago, IL 60064, USA.

*Corresponding author: benoit.cardinal-david@abbvie.com

\section{Table of Contents}

General Procedure for Small Scale Batch Nitration Experiments..............................S-2

Diagram for Scale-up Nitration in Flow with CSTR .....................................

Details on the CSTR Reactor Used for Flow Chemistry (Nitration) ...............................3

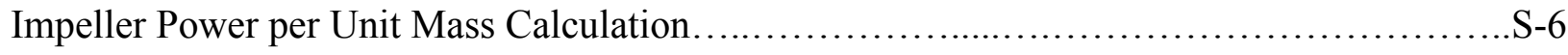

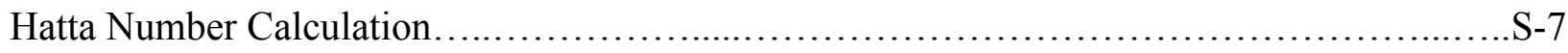

General Procedure for Small Scale Batch Formylation Experiments........................... -8

Laboratory-Scale Batch Formylation Experiment Results.....................................

General Procedure for Small Scale CSTR Flow Formylation Reactions.........................S-10

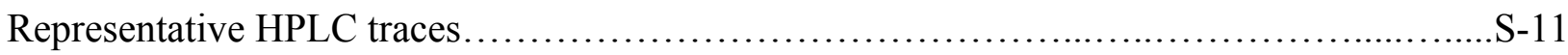




\section{General Procedure for Laboratory-Scale Batch Nitration Experiments}

To an Easymax 102 reactor was added concentrated sulfuric acid $(1 \mathrm{~mL}$ per $2.38 \mathrm{mmol}$ of 1methyl-4-trifluoromethylbenzene) and stirred with the desired impeller speed . Potassium nitrate (1 equiv) was then added slowly to mixture maintaining a temperature of approximately $20^{\circ} \mathrm{C}$. To the homogeneous solution, was then added 1-methyl-4-trifluoromethylbenzene (1 equiv) in a single portion and the temperature monitored with an exotherm of $\sim 5^{\circ} \mathrm{C}$. After 10 minutes, the reaction mixture was sampled by withdrawing a $5 \mu \mathrm{L}$ aliquot and diluting with $2 \mathrm{~mL}$ of 1:1 acetonitrile:water. HPLC analysis was used to evaluate the conversion of the starting material.

\section{Diagram for scale-up nitration in flow with CSTR}

The diagram in Figure S1 illustrates the set-up for the flow nitration process. In addition to the reaction setup, a 10 gallon canister filled with heptane was placed upstream of the CSTR for an emergency action procedure. This procedure would have been used in case of a pump or chiller failure. For example, if the feed of 1-methyl-4-trifluoromethylbenzene would accidentally stop, the remaining substrate in the CSTR would be exposed to an excess nitrating agent. The addition of heptane to the CSTR would transfer the substrate in the heptane layer (the substrate partitions favorably in the organic layer) to mitigate the risk of over-nitration and associated safety concerns. 


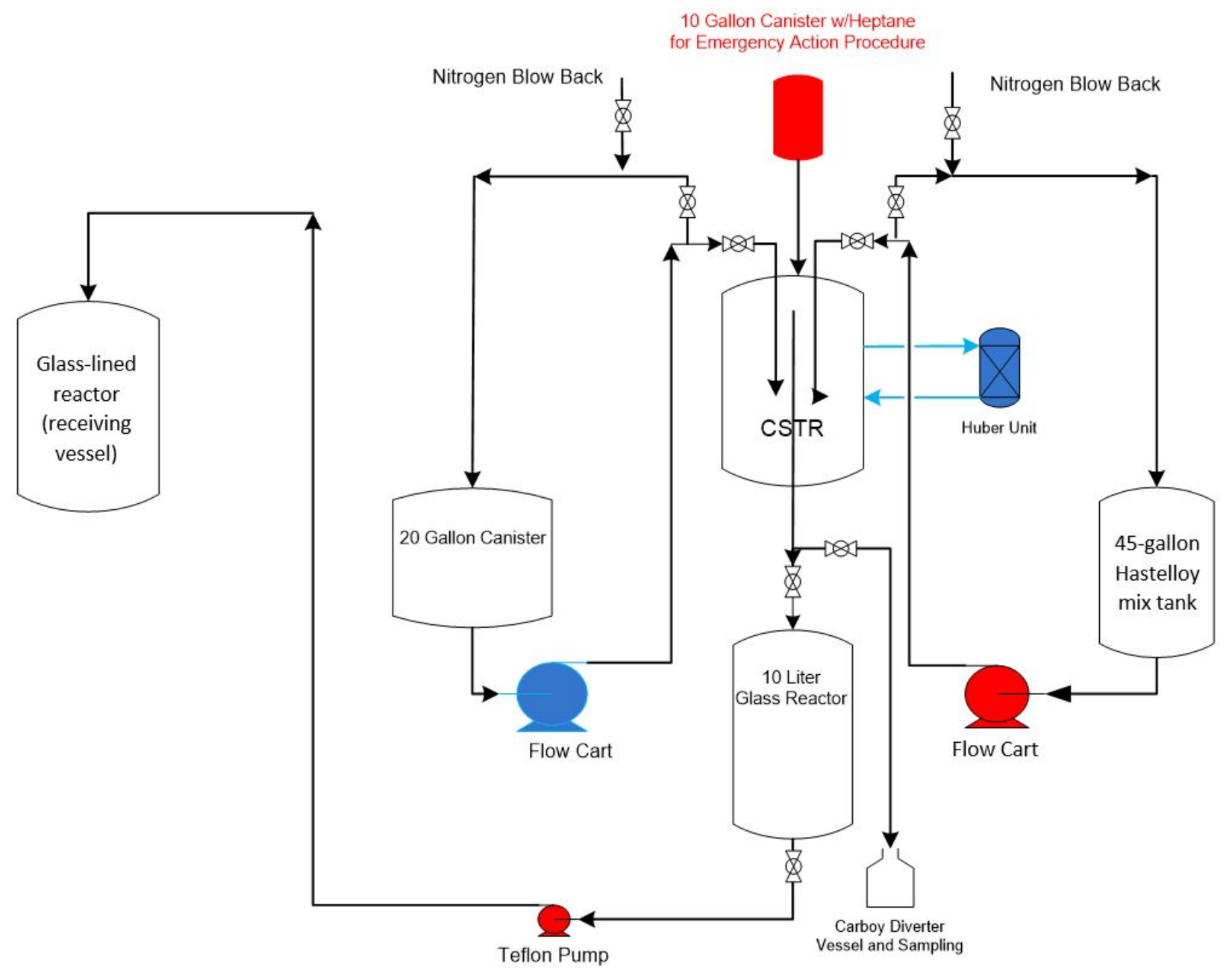

Figure S1: Diagram for scale-up nitration in flow with CSTR

\section{Details on the CSTR Reactor Used for Flow Chemistry (Nitration)}

The CSTR reactor used for the flow nitration is a 2 L Hastelloy Parr reactor, model 4330, which was customized according to the pictures below (Figures S2 and S3). Figure S3 shows the various components of the reactor. The dip tubes were adjusted such that the reagent feeds are away from the outlet and close to the bottom agitator to maximize the dispersion. 

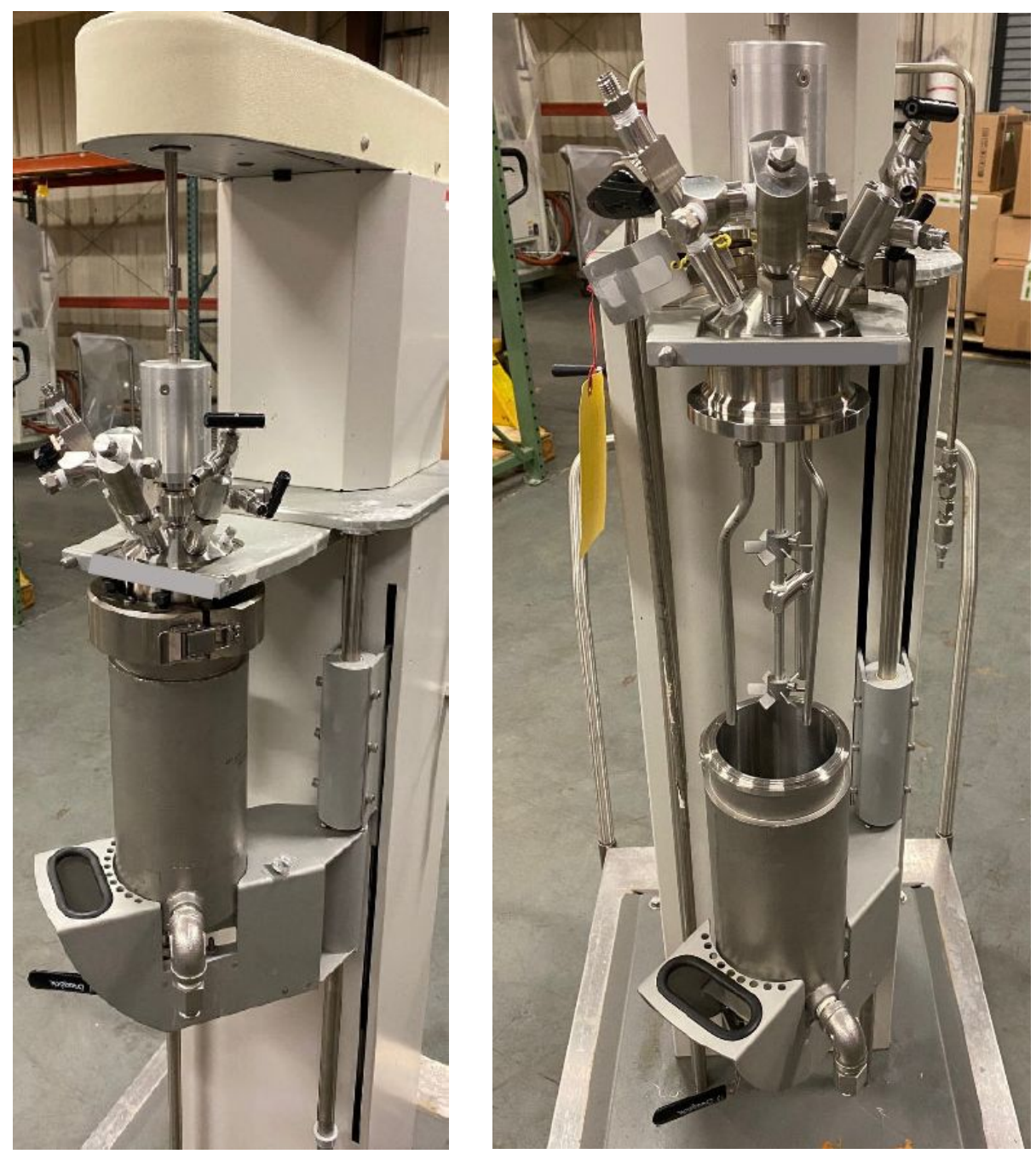

Figure S2: 2 L Parr Reactor Used for CSTR. 


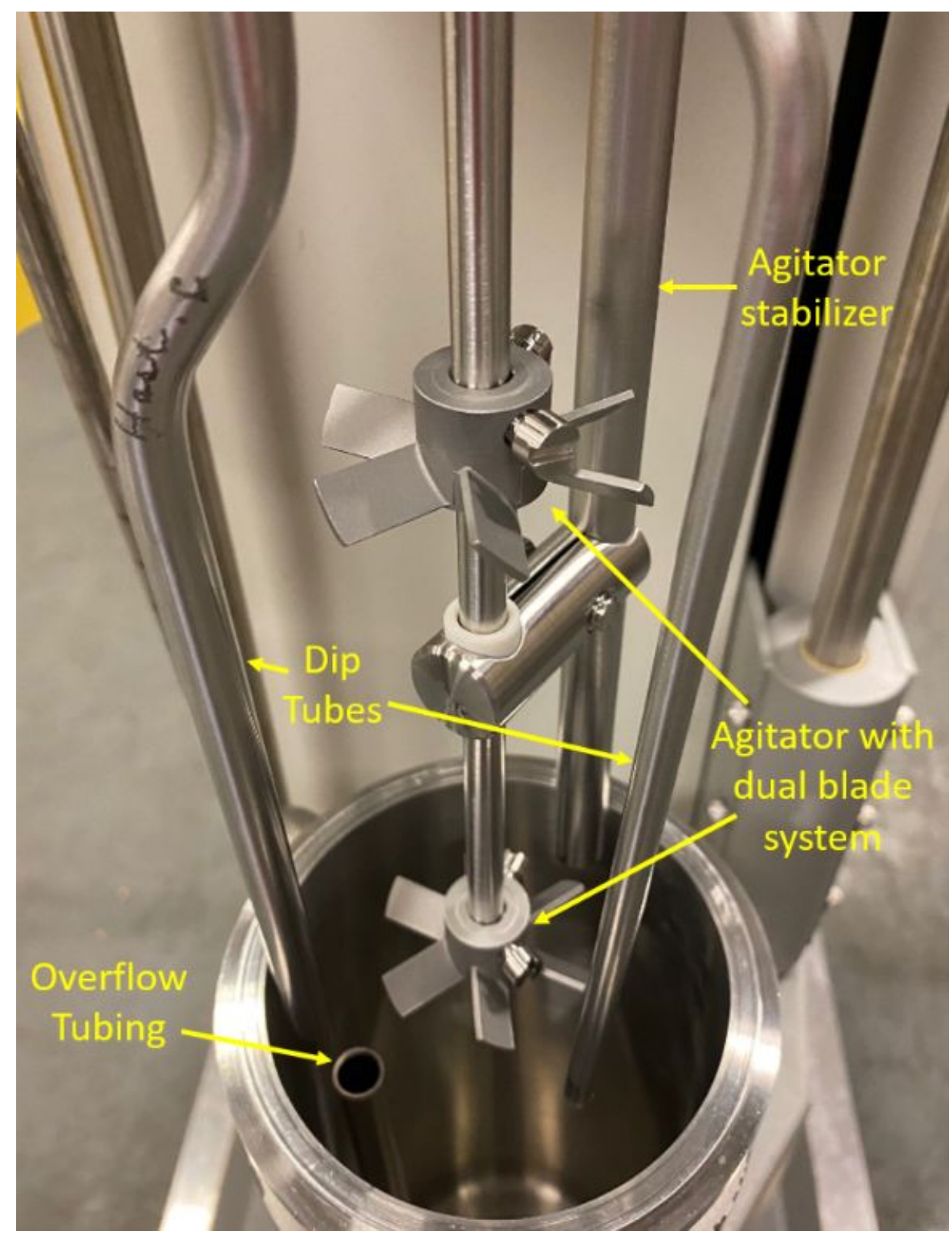

Figure S3: 2 L Parr Reactor with Components 


\section{Impeller Power per Unit Mass Calculation}

The general formula for calculation of impeller power is as follows:

$$
P=P_{o} \rho n^{3} d^{5}
$$

Where:

$P=$ power imparted by impeller in the reactor (Watt)

$P_{o}=$ Impeller power number

$\rho=$ Density of reaction mixture $\left(\mathrm{kg} / \mathrm{m}^{3}\right)$

$n=$ impeller rotation speed (RPS)

$d=$ impeller diameter $(\mathrm{m})$

$P_{o}$ is a function of various parameters such as impeller type, baffling, liquid holdup, etc. and was determined using the Dynochem software. 


\section{Hatta Number Calculation}

The general methodology used for Hatta number calculation is described in detail from Quadros and collaborators. ${ }^{1}$

$$
H a=\sqrt{\frac{\text { Reaction rate in film }}{\text { Diffusion rate in film }}}=\frac{\sqrt{k D}}{k_{L}}
$$

Where the Diffusion coefficient $D\left(\mathrm{~m}^{2} \mathrm{~s}^{-1}\right)$ is defined as:

$$
D=\frac{7.4 \times 10^{-18}(\phi M)^{0.5} T}{V_{b}^{0.6} \mu_{a q}^{0.8}}
$$

And where: $\phi M=2.6 x_{W} M_{W}+2.0 x_{S} M_{S}+1.05 x_{N} M_{N}$

$x_{W}=$ mole fraction of water

$M_{W}=$ molecular weight of water $\left(\mathrm{kg} \mathrm{mol}^{-1}\right)$

$x_{S}=$ mole fraction of sulfuric acid

$M_{S}=$ molecular weight of sulfuric acid $\left(\mathrm{kg} \mathrm{mol}^{-1}\right)$

$x_{N}=$ mole fraction of substrate

$M_{N}=$ molecular weight of substrate $\left(\mathrm{kg} \mathrm{mol}^{-1}\right)$

$T=$ temperature $(\mathrm{K})$

$V_{b}=$ molar volume of substrate $\left(\mathrm{m}^{3} \mathrm{~mol}^{-1}\right)$

$\mu_{a q}=$ viscosity of aqueous phase (Pa s)

$k=$ pseudo-first order reaction rate constant $\left(\mathrm{s}^{-1}\right)$

Where the Mass transfer coefficient $k_{L}\left(\mathrm{~m} \mathrm{~s}^{-1}\right)$ is defined as:

$$
k_{L}=0.13\left[\left(\frac{P}{V_{a q}}\right)\left(\frac{\mu_{a q}}{\rho_{a q}^{2}}\right)\right]^{1 / 4}\left(\frac{\mu_{a q}}{\rho_{a q} D}\right)^{-2 / 3}
$$

$V_{a q}=$ volume of aqueous phase $\left(\mathrm{m}^{3}\right)$

$\rho_{a q}=$ density of aqueous phase $\left(\mathrm{kg} \mathrm{m}^{-3}\right)$ 


\section{General Procedure for Laboratory-Scale Batch Formylation Experiments}

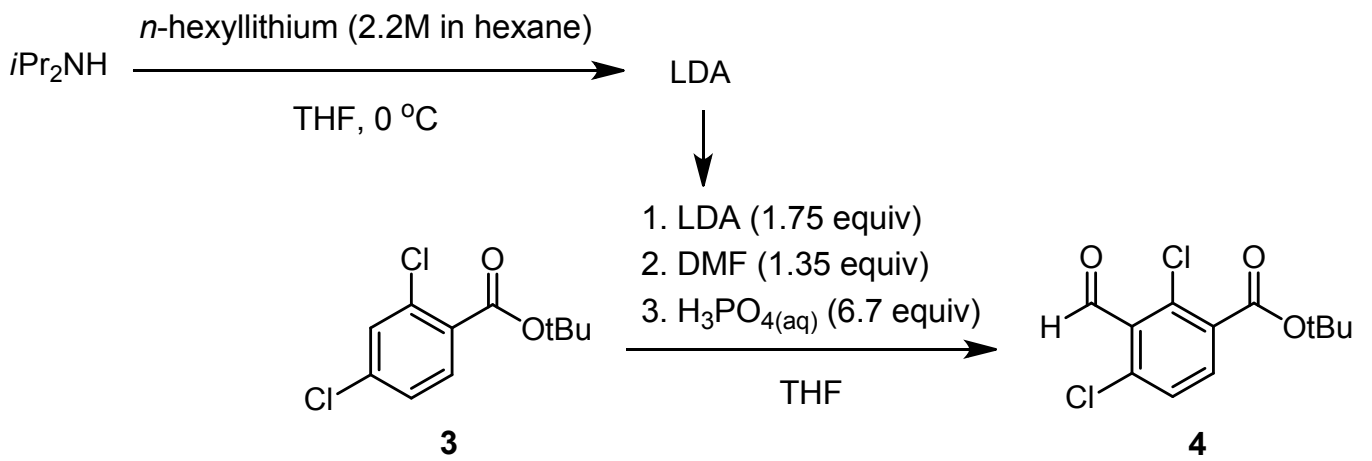

Figure S4: Formylation reaction with $n$-hexyllithium

LDA stock solution preparation: To a $100 \mathrm{~mL}$ Easy-Max reactor flushed with $\mathrm{N}_{2}$ was charged $N, N$ diisopropylamine $(6.12 \mathrm{~g}, 60.5 \mathrm{mmol})$ and THF $(61.61 \mathrm{~g})$ at $0{ }^{\circ} \mathrm{C} . \quad N$-hexyllithium $(25 \mathrm{~mL}$ of 2.2 M solution in heptane, $55.0 \mathrm{mmol}$ ) was added dropwise to the reactor while stirring at $700 \mathrm{rpm}$ and maintaining the internal temperature at $\leq 2{ }^{\circ} \mathrm{C}$. After the addition was complete, the stock solution was stored at $-30{ }^{\circ} \mathrm{C}^{2}$ The titer of the LDA solution was determined with menthol/phenanthroline before using in the formylation reaction.

Formylation reaction:

The following solutions were prepared:

1- Solution 1: $1 \mathrm{M}$ Ester in THF;

2- Solution 2: 1 M DMF in THF;

3- Solution 3: $6.7 \mathrm{M} \mathrm{H}_{3} \mathrm{PO}_{4}$ in $\mathrm{H}_{2} \mathrm{O}\left(50 \mathrm{w} / \mathrm{w} \% \mathrm{H}_{3} \mathrm{PO}_{4}\right)$.

A $40 \mathrm{~mL}$ vial was equipped with a stir bar, capped with a septum, equipped with a thermocouple, and flushed with $\mathrm{N}_{2}$. The vial was immersed in a temperature-controlled bath at the desired temperature. $4.0 \mathrm{~mL}$ of $0.5 \mathrm{M}$ LDA stock solution was charged to the vial, and the internal temperature was allowed to equilibrate to the bath temperature. Then, $1.1 \mathrm{~mL}$ of Solution 1 (1.1 mmol ester) was charged to the vial. The reaction was mixed for a desired Residence Time $1\left(\tau_{1}\right)$. Then, $1.5 \mathrm{~mL}$ of the Solution $2(1.5 \mathrm{mmol} \mathrm{DMF})$ was charged to the vial. The reaction was mixed for a desired Residence Time $2\left(\tau_{2}\right)$. The reaction was then quenched with the addition of $3.0 \mathrm{~mL}$ of Solution 3. The mixture was extracted with MTBE, and the organic layer was dried over $\mathrm{Na}_{2} \mathrm{SO}_{4}$ and filtered. The resulting organic layer was then assayed for product content by HPLC. ${ }^{3}$ 


\section{Laboratory-Scale Batch Formylation Experiment Results}

The data in Table 1 below was collected using the protocol in page S3. The data was used for Figure 6 in the manuscript.

Table S1. Summary of batch experiments.

\begin{tabular}{|c|c|c|c|c|c|}
\hline Entry & $\begin{array}{c}\text { Temperature } \\
\left({ }^{\circ} \mathrm{C}\right)\end{array}$ & $\begin{array}{c}\text { Residence } \\
\text { Time } 1\left(\tau_{1}\right), \\
\min \end{array}$ & $\begin{array}{c}\text { Residence } \\
\text { Time 2 }\left(\tau_{2}\right), \\
\min \end{array}$ & $\begin{array}{c}\text { PAY } \\
(\%)\end{array}$ & $\begin{array}{c}\text { Conversion } \\
(\%)\end{array}$ \\
\hline 1 & -50 & 3.2 & 10.0 & 56 & 87 \\
\hline 2 & -50 & 4.0 & 1.5 & 62 & 91 \\
\hline 3 & -50 & 6.0 & 1.5 & 70 & 95 \\
\hline 4 & -50 & 6.0 & 6.0 & 75 & 93 \\
\hline 5 & -50 & 6.0 & 10.0 & 71 & 95 \\
\hline 6 & -50 & 10.0 & 1.5 & 74 & 94 \\
\hline 7 & -40 & 3.0 & 2.0 & 64 & 94 \\
\hline 8 & -40 & 2.3 & 1.0 & 63 & 89 \\
\hline 9 & -40 & 3.3 & 10.0 & 65 & 94 \\
\hline
\end{tabular}




\section{General Procedure for Laboratory-Scale CSTR Flow Formylation Experiments}

Lab scale CSTRs in series were constructed by piercing a septum of a 2-dram vial with Teflon tubing as shown below where Feed \#1 is the LDA, Feed \#2 is the ester solution and Feed \#3 is the DMF solution. The vials were placed in a cooling bath at -45 to $-50{ }^{\circ} \mathrm{C}$. The transfer from one CSTR to the other was achieved with $\mathrm{N}_{2}$ pressure, forcing the excess liquid out via a Teflon tube.

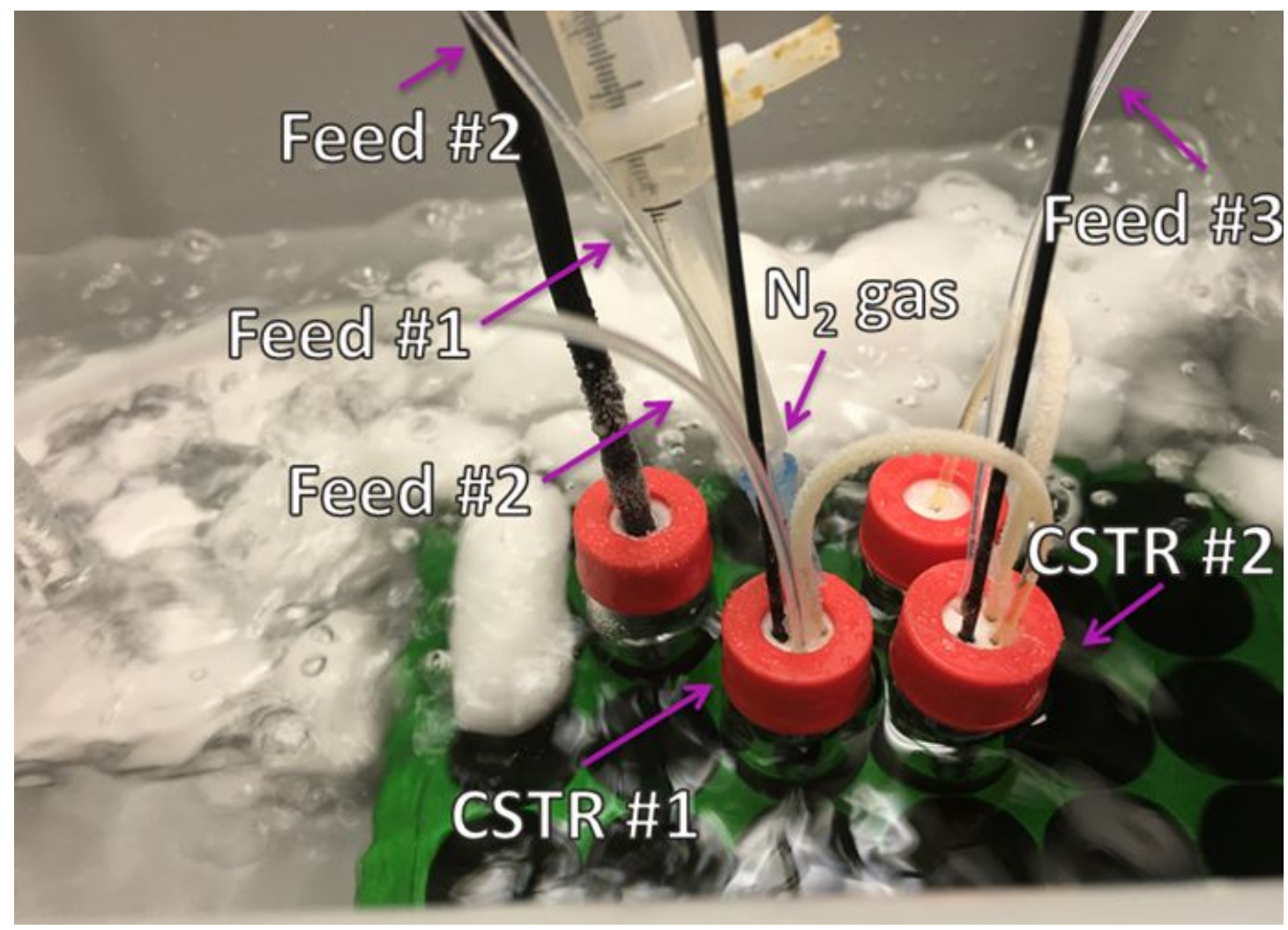

Figure S5: Small scale flow CSTR formylation set-up. 


\section{Representative HPLC Traces}

Crude reaction mixtures were analyzed by Agilent 1200 HPLC system comprising of an Agilent Binary pump, degasser, column compartment, autosampler and diode-array detector equipped with an Ascentis Express C18 (4.6 mm $\times 15 \mathrm{~cm}, 2.7$ micron).

\section{Representative HPLC Traces for the CSTR Flow Nitration}

Mobile phase A was $0.1 \%$ phosphoric acid in water and mobile phase B was acetonitrile. Flow rate was $1.0 \mathrm{~mL} / \mathrm{min}$ with a column temperature of $40{ }^{\circ} \mathrm{C}$. The gradient was as follows: $0-1 \mathrm{~min}$ $40 \% \mathrm{~B}, 1-7 \min 40-90 \% \mathrm{~B}, 7.0-7.1 \min 90-40 \% \mathrm{~B}$.

\section{$\underline{\text { Retention Times: }}$}

- $\quad$ Starting material: $\quad 4.57 \mathrm{~min}$

- Product: $\quad 3.84 \mathrm{~min}$

- Dinitro product: $3.53 \mathrm{~min}$

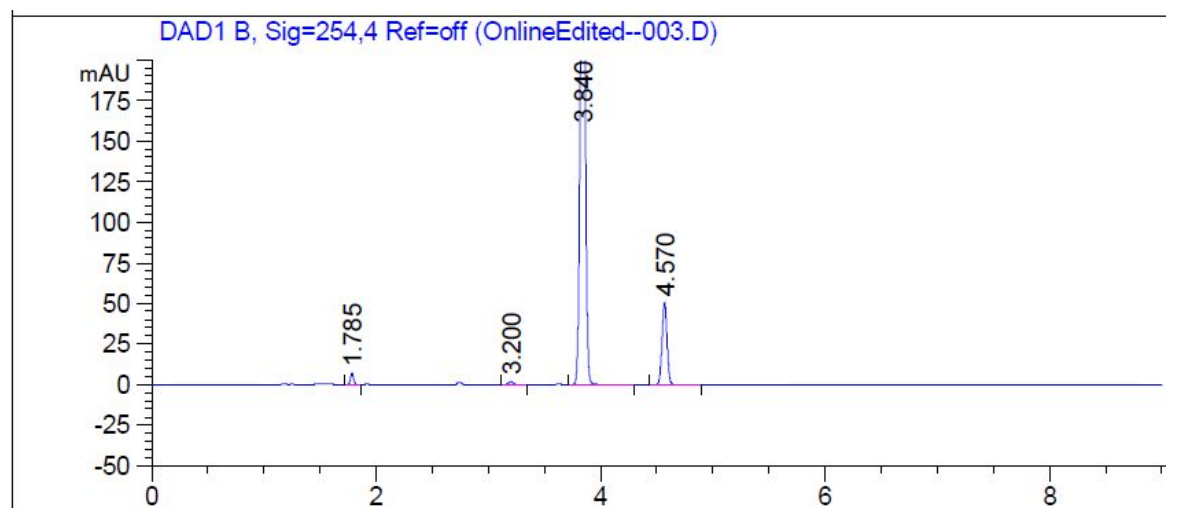

Figure S6: Nitration reaction at $75 \%$ conversion: 


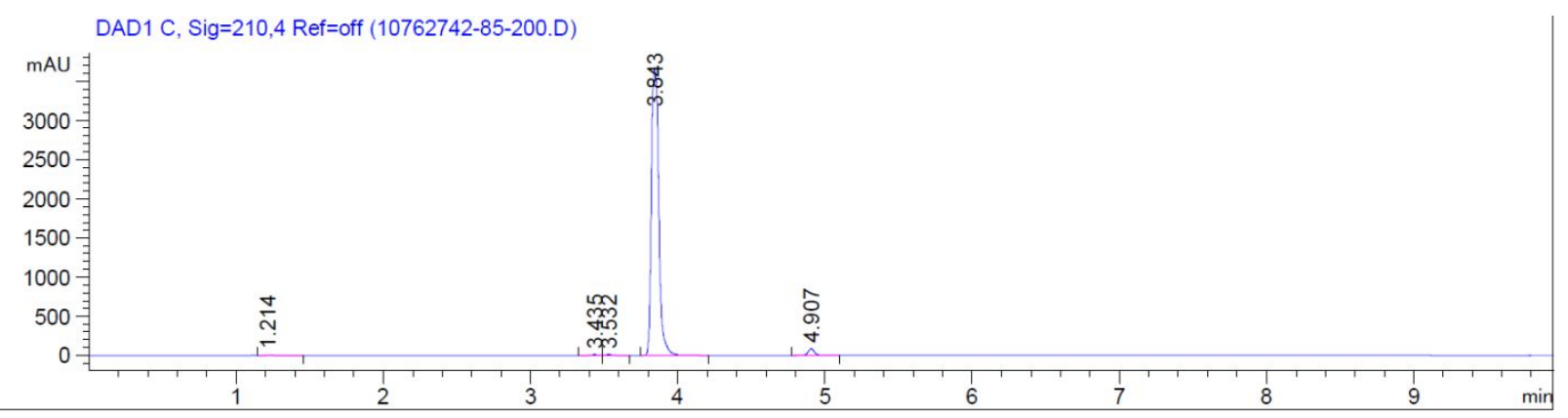

Figure S7: Nitration reaction at end of reaction:

\section{Representative HPLC Trace for the CSTR Flow Formylation}

Mobile phase A was $0.1 \%$ perchloric acid in water and mobile phase $\mathrm{B}$ was acetonitrile. Flow rate was $1.0 \mathrm{~mL} / \mathrm{min}$ with a column temperature of $35^{\circ} \mathrm{C}$. The gradient was as follows: $0 \mathrm{~min} 10 \% \mathrm{~B}$, $0-8 \min 10-90 \% \mathrm{~B}, 8-18 \min 90 \% \mathrm{~B}, 18.0-18.1 \min 90-10 \% \mathrm{~B}$.

HPLC trace below was obtained after work-up; product is 81 area\% @ $210 \mathrm{~nm}$.

Retention Times:

- $\quad$ Starting material: $\quad 10.20 \mathrm{~min}$

- Product: $\quad 9.05 \mathrm{~min}$

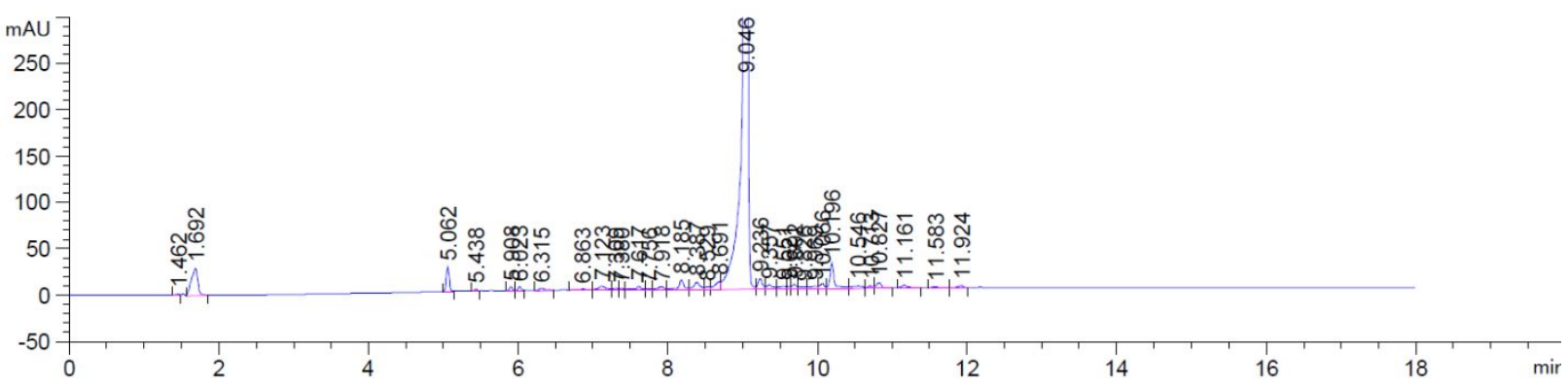

Figure S8: Representative HPLC trace after work-up of the CSTR flow formylation 


\section{REFERENCES}

${ }^{1}$ Quadros, P. A.; Oliveira, N. M. C.; Baptista, C. M. S. G. Continuous adiabatic industrial benzene nitration with mixed acid at a pilot plant scale, Chem. Eng. J. 2005, 108, 1-11.

2 The freshly prepared LDA solution had a limited shelf life. Experiments showed that LDA is stable for 4 days when stored at approximately $-25^{\circ} \mathrm{C}$. Prolonged storage periods or warmer temperatures led to a darkening of the LDA solution, as well as decreased performance in the formylation reaction.

${ }^{3}$ Determined with a solution of a standard sample of the product at a known concentration. 